\title{
ON ASYMMETRIC ENTIRE FUNCTIONS
}

Q. I. RAHMAN

Let $p(z)$ be a polynomial of degree $n$ having all its zeros in $|z| \leqq 1$. Then according to Walsh's generalization of Laguerre's theorem [3, Lemma 1, p. 13]

$$
\frac{p^{\prime}\left(e^{i \theta}\right)}{p\left(e^{i \theta}\right)}=\frac{n}{e^{i \theta}-w}
$$

for points $e^{i \theta}$ other than zeros of $p(z)$ where $|w| \leqq 1$. Hence $\left|e^{i \theta}-w\right|$ $\leqq 2$ and

$$
\left|\frac{p^{\prime}\left(e^{i \theta}\right)}{p\left(e^{i \theta}\right)}\right| \geqq \frac{n}{2} .
$$

If $\max _{0 \leqq \theta<2 \pi}\left|p\left(e^{i \theta}\right)\right|=\left|p\left(e^{i \theta_{0}}\right)\right|$, then

(1) $\max _{0 \leqq \theta<2 \pi}\left|p^{\prime}\left(e^{i \theta}\right)\right| \geqq\left|p^{\prime}\left(e^{i \theta_{0}}\right)\right| \geqq \frac{n}{2}\left|p\left(e^{i \theta_{0}}\right)\right|=\frac{n}{2} \max _{0 \leqq \theta<2 \pi}\left|p\left(e^{i \theta}\right)\right|$.

We shall obtain a result for entire functions which generalizes (1). To see what to expect, note that $p\left(e^{i z}\right)$ is an entire function $f(z)$ of exponential type of a special kind: if $h(\theta)$ is its indicator, we have $h(-\pi / 2)=n$, but $h(\pi / 2) \leqq 0$. If $p(z)$ has no zeros in $|z|>1, f(z)$ has no zeros in $y<0$.

Let us consider, then, entire functions $f(z)$ of exponential type $\tau$ with 1.u.b. $-\infty<x<\infty|f(x)|=1, h(-\pi / 2)=n, h(\pi / 2) \leqq 0$, and $f(z) \neq 0$ for $y<0$.

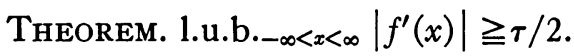

To prove the theorem put $g(z)=f(z) e^{-i r z / 2}$. Then l.u.b. ${ }_{-\infty<x<\infty}|g(x)|$ $=1$ and $g(z)$ is of exponential type $\tau / 2$; moreover the indicator $h_{g}$ of $g$ satisfies $h_{g}(-\pi / 2) \geqq h_{g}(\pi / 2)$. Since $g(z)$ has no zeros for $y<0$ it belongs to the class $P$ discussed in $[1$, pp. 129-131] and can be represented in the form

$$
g(z)=A z^{m} e^{c z} \prod_{n=1}^{\infty}\left(1-\frac{z}{z_{n}}\right) \exp \left\{z \operatorname{Re}\left(\frac{1}{z_{n}}\right)\right\}
$$

where $\operatorname{Im}\left(z_{n}\right) \geqq 0$ and $2 \operatorname{Im} c=h_{\theta}(-\pi / 2)-h_{\theta}(\pi / 2) \geqq 0$. Thus for $-\infty<x<\infty$

Received by the editors March 29, 1962. 


$$
\operatorname{Im}\left\{\frac{g^{\prime}(x)}{g(x)}\right\}=\operatorname{Im} c+\sum_{n=1}^{\infty} \frac{b_{n}}{\left(x-a_{n}\right)^{2}+\left(y-b_{n}\right)^{2}},
$$

where $z_{n}=a_{n}+i b_{n}, b_{n} \geqq 0$. The right hand side is non-negative. Hence

$$
\operatorname{Im}\left\{\frac{f^{\prime}(x)}{f(x)}\right\}=\operatorname{Im}\left\{\frac{g^{\prime}(x)}{g(x)}\right\}+\frac{\tau}{2} \geqq \frac{\tau}{2} .
$$

Let $\epsilon$ be any number $>0$. There exists a number $x_{0}$ such that $-\infty$ $<x_{0}<\infty$, and $\left|f\left(x_{0}\right)\right|>1-\epsilon$. So that

$$
\underset{-\infty<x<\infty}{\text { l.u.b. }}\left|f^{\prime}(x)\right| \geqq\left|f^{\prime}\left(x_{0}\right)\right|=\left|f\left(x_{0}\right)\right|\left|\frac{f^{\prime}\left(x_{0}\right)}{f\left(x_{0}\right)}\right| \geqq(1-\epsilon) \frac{\tau}{2} .
$$

Making $\epsilon \rightarrow 0$ we get the result.

A theorem of Boas [2, Theorem 2] states that if $f(z)$ is an entire function of exponential type $\tau$ with $|f(x)| \leqq 1$ for real $x, h(-\pi / 2)=\tau$, $h(\pi / 2)=0$, and $f(z) \neq 0$ for $y>0$, then for real $x$

$$
\left|f^{\prime}(x)\right| \leqq \frac{\tau}{2}
$$

Combining this result with the conclusion of our theorem we obtain the following

CoROllary. If $f(z)$ is an entire function of exponential type $\tau$ with l.u.b. $-\infty<x<\infty|f(x)|=1, h(-\pi / 2)=\tau, h(\pi / 2)=0$, and $f(z)$ has all its zeros on the real axis, then

$$
\underset{-\infty<x<\infty}{\text { l.u.b. }}\left|f^{\prime}(x)\right|=\frac{\tau}{2} .
$$

\section{REFERENCES}

1. R. P. Boas, Jr., Entire functions, Academic Press, New York, 1954.

2. - Inequalities for asymmetric entire functions, Illinois J. Math. 1 (1957), 94-97.

3. J. L. Walsh, The location of critical points of analytic and harmonic functions, Amer. Math. Soc. Colloq. Publ. Vol. 34, Amer. Math. Soc., Providence, R. I., 1950.

Regional Engineering College, SRinagar, India 